\title{
On Impact of the Ventilation Components on the Ventilation Rate in a Passive Solar Energy Efficient House
}

\author{
Golden Makaka*, V Xuza, E Meyer and P Mukumba \\ University of fort Hare, South Africa

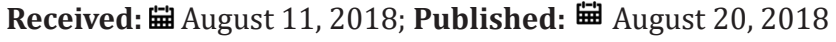 \\ *Corresponding author: Golden Makaka, University of fort Hare Private Bag X1314 Alice, 57000, South Africa
}

Abstract

One of the deficiencies of the low-cost housing in South Africa is poor ventilation efficiency. These houses are characterized by poor indoor air quality, and this is mainly attributed to poorhouse design with no regard to orientation and prevailing winds. This paper evaluates the impact of the ventilation components on the ventilation rate in a passive solar energy efficient house. Windows were found to have a higher impact on the ventilation rates than doors. Results also indicate that the house meets the South African residential ventilation rates specifications. The indoor carbon dioxide concentration monitored over night was found to be $0.248 \%$, which is less than the maximum range limit of $0.500 \%$

\section{Introduction}

Ventilation is usually reduced during the winter period due to cold weather and the indoor environment is starved of fresh air. There is need to have efficient heating system to guarantee good air quality. Many rural communities in South Africa use coal as an energy heat source and this result in the contamination of the indoor air in addition to high indoor temperature swings resulting in thermally uncomfortable environment, the low-cost housing in South Africa have poor indoor air quality and natural light distribution. The poor ventilation efficiency of these houses is due to poorhouse design. Quality of indoor environment depends significantly on several aspects, which include ventilation rate and lighting [1]. Site factors such as temperature, wind speed and direction, orientation of the house, and construction type have significant varying impacts on the natural infiltration [2]. House operation plays a key role in controlling a comfortable indoor environment. A low-cost energy efficient passive solar house was constructed on a site that experience westerly prevailing winds and the house was designed to make use of these winds to control the indoor environment thermal conditions.

Passive solar design uses solar radiation to heat and light homes without mechanical or electrical devices. It is usually part of the design of the building itself, and by using certain materials and the correct placement of windows, the thermal performance of the house can be improved. A successful passive solar building needs to be well insulated to make best use of the sun's energy [3] and all stake holders need to be involved from design stage through the construction process. The result is a quiet and comfortable space, free of drafts and cold spots. Passive solar design can also achieve summer cooling through the correct management of the ventilation components. This is enhanced by convective air currents, which are created by the natural tendency of hot air to rise [4]. In winter when heating is required, the sun is low in the sky, and the north facing windows allow the solar radiation to penetrate indoor, heating the thermal mass which later at night radiate thermal radiation thus heating the indoor environment. In summer, north-facing windows can be shaded by roof overhangs or awning keeping out the high hot summer sun. Much of a building's heat is lost through its windows. Majority of the windows in a passive solar building are located on the north wall to maximise solar heat gain in winter. Applying low solar absorptive paint to the outer roof surface and using aluminum foil on the inside lowers emissivity and helps to create better thermal performance. A good house design must safeguard health and safety by providing enough airspace, ventilation, insulation, etc. and most importantly to involve the end users in the design process.

The low-cost energy efficient passive solar house was designed to rely on natural ventilation and building ventilation components were positioned to capture the prevailing winds. In South Africa night air temperature can be lower than the comfort temperature $\left(<16^{\circ} \mathrm{C}\right)$ and can be used to dissipate the heat accumulated during the day. Human activities such as cooking, bathing, breathing, and maintaining houseplants introduce indoor pollutants [5]. Pollutants can build up to levels that may negatively impact human health unless they are removed or diluted with fresh outside air. It is therefore necessary to evaluate the indoor air quality and improve the daily management of the ventilation components. 
To maintain comfortable indoor environment buildings must have minimum amount of air exchange rate to control humidity, cooling and to eliminate orders. The South African Residential Ventilation Building Code recommends an average natural infiltration rate of $0.35 \mathrm{~m}^{3} / \mathrm{h} \cdot \mathrm{m}^{2}$ (air change rate) and an indoor carbon dioxide concentration less than 0.500\% [Agreement South Africa]. This paper evaluates the impact of the ventilation components on the ventilation rate in a passive solar energy efficient housing. For the evaluation of the ventilation efficiency the tracer gas (carbon dioxide) method was used. Although the tracer gas (carbon dioxide) method is not all that accurate it allows one to have good estimates of the ventilation rate within a room.

\section{Short Description of the House}

The floor plan measured $6880 \mathrm{~mm}$ by $6580 \mathrm{~mm}$, giving an approximate area of $45 \mathrm{~m}^{2}$. Figure 1 shows the floor plan of the experimental passive solar house. The house has two standard doors and a total of six windows, i.e., two large windows on the north (front), two medium windows on the south wall, and one small window on the west and another small window on the eastern wall. One of the doors is on the north wall and the other on the west wall. An open plan layout was adopted to optimize natural ventilation. Mechanical ventilation systems were avoided to keep the running cost of the house low. At the time of measurement, four people were staying in the house, i.e., an elderly couple, an eightyear-old boy and an unemployed middle-aged man.

\section{Airflow Rates}

Air may enter a measured zone not only directly from outdoors, but also from neighboring zones, whose $\mathrm{CO}_{2}$ concentration may differ from that of the outdoor air. These inter-zone airflows may influence the $\mathrm{CO}_{2}$ concentration in the measured zone [6]. The concept of "equivalent outdoor airflow rate" is introduced to offset this inconvenience. It corresponds to the outdoors airflow rate that would result in the same $\mathrm{CO}_{2}$ concentration in the measured room without inter-zone air flows. An adult person produces on average (i.e. quiet or doing light work, about $100 \mathrm{~W}$ metabolic rate) about $20 \mathrm{l} / \mathrm{h}$ carbon dioxide. At steady state, assuming that occupants are the only $\mathrm{CO}_{2}$ sources, the equivalent airflow rate per person, $\mathrm{Q}_{\mathrm{e}}$, is related to $\mathrm{CO}_{2}$ concentration ( $\mathrm{Ci}$ indoors and Co outdoors) by [7]:

$$
Q_{e}=\frac{S}{C_{i}-C_{0}}
$$

where $\mathrm{S}$ is the $\mathrm{CO}_{2}$ source strength, i.e. about $20 \mathrm{l} / \mathrm{h}$. Assuming a steady state (constant carbon dioxide concentration), equation 1 can be used to assess the equivalent outdoor airflow rate per person. Another way is to use the $\mathrm{CO}_{2}$ concentration records when there is no $\mathrm{CO}_{2}$ source in the building. During these periods, the concentration decays down to the background concentration, by dilution with the outdoor air flow. If there is good mixing and if the outdoor air flow rate is constant, the decay is exponential, and the factor corresponds to the air change rate and the concentration at any time $t$, is given as:

$$
C=C_{0} e^{-\mu t}
$$

where is the air exchange rate, is the initial concentration above the background concentration. Taking logarithms both sides of equation 2 and differentiating with respect to time the air exchange rate can be approximated by the following expression:

$$
\Delta \operatorname{Ln}(C)=-\mu \Delta t
$$

Plots of against will a produce a straight line whose gradient is equal to air exchange rate. If the outdoor airflow rate is not constant, which is mostly the case, the decrement calculated from two measurements of concentration taken at time t1 and t2 provides an unbiased estimate of the average equivalent outdoor specific airflow.

\section{Indoor Air Quality}

The amount of $\mathrm{CO}_{2}$ indoor determines the air quality and its concentration indicate the ventilation rate within a space. The time it takes for a room to reach equilibrium depends on the number of people in a room or building zone, the volume of the space and the ventilation rate within the space. If the room is poorly ventilated and has very low occupant densities, it may take several hours before the equilibrium level is reached. Table 1 gives a guide to the carbon dioxide concentration levels. To evaluate excessive indoor air pollution and its health effects, it is important to identify the pollutants present in a room or building and to determine how the levels of each vary with time. Outdoors levels of $\mathrm{CO}_{2}$ are relatively constant and range between (350 to $600 \mathrm{ppm}$ ); inside levels will never be below the outside level $[8,9]$. The amount of $\mathrm{CO}_{2}$ in the space can give an indication of the number of persons within the space.

Table 1: Guide values for $\mathrm{CO}_{2}$ concentration.

\begin{tabular}{|c|c|}
\hline Concentration & Condition \\
\hline$\sim 40.000 \mathrm{ppm}$ & Proportion in exhaled human breath $(20 \mathrm{l} / \mathrm{h})$ \\
\hline $5.000 \mathrm{ppm}$ & Limit of $\mathrm{CO}_{2}$ concentration within a space \\
\hline $400 \mathrm{ppm}$ & Fresh, natural ambient air \\
\hline
\end{tabular}

\section{Methodology}

\section{Ventilation Rate}

Tracer gas tests were conducted over a period to measure air change rates. Carbon dioxide was injected into the house and its concentration monitored over time to determine how quickly the gas dissipates through the house's envelope. Non-dispersive infrared absorbance (NDIR) gas sensors were used to monitor indoor carbon dioxide concentration. A carbon dioxide sensor was placed in the centre of the house at a height of about $0.45 \mathrm{~m}$ above the floor. A pump was used to pump the indoor air into the sensor at a rate of about $300 \mathrm{ml} / \mathrm{min}$. To investigate the effects of each of the ventilation components, i.e., windows and doors, the ventilation rate tests were done in four phases. A carbon dioxide sensor connected to CR1000 datalogger and a computer was used to monitor the carbon dioxide concentration in the house. Figure 1 shows the experimental setup. From Figures $1 \& 2$ (the floor plan) it can be noted that there is one door on the west side of the house and another door on the northern side. The position of the doors was meant to capture the annual prevailing winds thus controlling the indoor thermal comfort. 


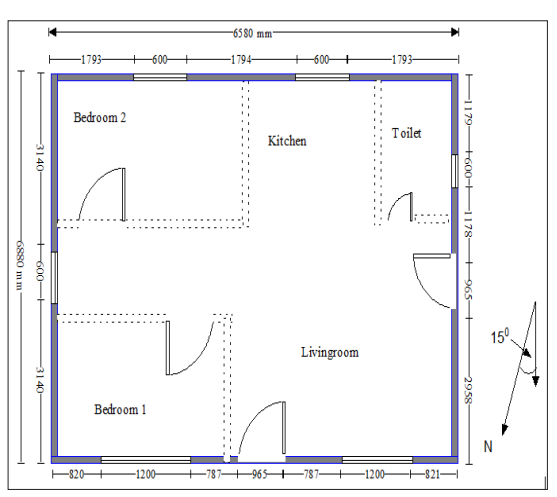

Figure 1: House floor plan.

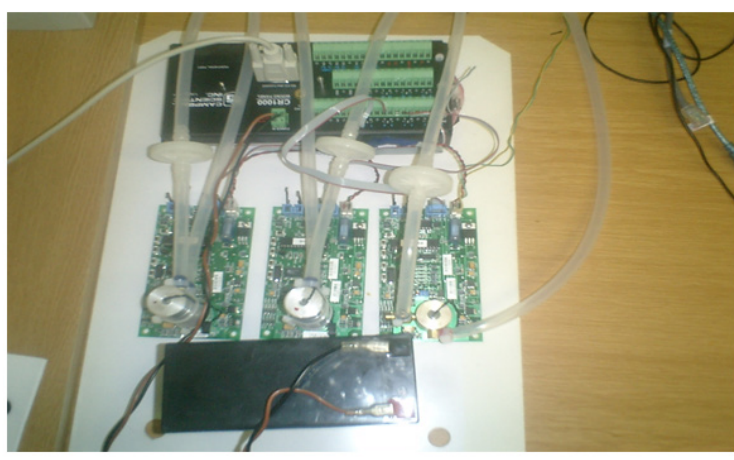

Figure 2: Carbon dioxide sensor.

\section{Phase One}

Carbon dioxide gas was injected into the house when all doors and windows were closed, and a fan was used to mix the air in the house for about 5 minutes. The operation of the fan was intended to evenly distribute the initial tracer dose throughout the space for the calculation of exchange rates. Windows and doors were then widely opened (that is, through 900C) and carbon dioxide concentration was recorded at a time interval of 1 minute until a constant carbon dioxide concentration was achieved.

\section{Phase Two}

Carbon dioxide was injected into the house with doors and windows closed; a fan was switched on for 5 minutes to mix the air. Windows were then opened but keeping the doors closed and carbon dioxide concentration readings taken at 1-minute interval.

\section{Phase Three}

The procedure of phase 2 was repeated but doors were opened, and windows closed, and the carbon dioxide concentration recorded at a time interval of 1 minute.

\section{Phase Four}

The procedure cited in phase 2 was repeated but all windows and doors were closed, and carbon dioxide concentration recorded at 1-minute interval. In all the above cases it was not possible to inject equal amounts of the tracer gas as the equipment used could not allow the measurement of the amount of gas injected. Due to the different amount of the injected tracer gas, comparison was only done when the amount of the gas has decayed to the same level as in the before a given a level.

\section{Measurement of Air Quality}

The occupants of the house were of old age and they spend most of their time indoor. Therefore, adequate maintenance of indoor air quality (IAQ) through the correct management of the ventilation components of the house is of prime importance. To maintain adequate indoor air quality, it is essential to provide outside air to dilute indoor air pollutants and exhaust the contaminants along with moisture and odours. To assess the indoor air quality, the waste case was considered, i.e., the most likely time when the indoor air is mostly contaminated is at night when all the designed ventilation components would be closed and all the occupants being indoor. For the measurement of air quality, the carbon dioxide concentration was monitored over the whole night. Readings were recorded at 1-minute interval. Modern climate control can assure optimal air quality by adjusting the supply of fresh air based on the measurement of $\mathrm{CO} 2$ concentration in the indoor air. The $\mathrm{CO} 2-$ concentration is an important measure of indoor air quality.

\section{Results and Discussions}

\section{Ventilation Rate}

The tracer gas technique was used to measure the air exchange rate. Figures $3 \& 4$ illustrate the tracer gas concentration profiles measured for different ventilation component configurations, i.e., opening and closing of doors and windows. The average indoor and outdoor temperatures during these tests were, Tin $=20^{\circ} \mathrm{C}$ and Tout $=17^{\circ} \mathrm{C}$, and an average wind speed of $0.5 \mathrm{~m} / \mathrm{s}$ blowing from $\mathrm{W}$ (600 150) N. Figure 3 show the tracer gas concentration variation for configuration I, i.e., when both windows and doors were open. Results indicate that the concentration decays exponentially to the background concentration within a period of 18 minutes. If the west window and door are the only paths through which the westerly winds enter the house, then the mass air flow rate through the door and window is approximated by: $\dot{m}=C_{d} A \sqrt{2 \rho \Delta P}$. Taking the average air density to be $1.2 \mathrm{~kg} / \mathrm{m} 3$ and an average indoor and outdoor pressure difference of $4 \mathrm{~Pa}$. For wide-open windows and doors, the opening area is the sum of the windows and doors areas, which gives $2.06 \mathrm{~m} 2$, and taking the discharge coefficient $C_{d}=0.6$, the average mass airflow was found to be approximately $3.83 \mathrm{~kg} / \mathrm{s}$.

as

From Figure 3 it was observed that the closing of doors significantly reduced the carbon dioxide concentration decay rate implying a reduction in the ventilation rates achieved when both doors and windows were open. Opening windows and closing doors reduced the mass flow rate to $3.16 \mathrm{~kg} / \mathrm{s}$ (i.e. a reduction of $17 \%)$. This means doors play a significant role in the ventilation of the PSH. Figure 4 illustrates the decay of the tracer gas concentration for configurations III and IV, i.e., for open doors and closed windows, and for when both windows and doors were closed. Comparing configurations, I and III it was found that the opening of doors and closing windows reduced the mass flow rate from $3.83 \mathrm{~kg} / \mathrm{s}$ to $0.67 \mathrm{~kg} / \mathrm{s}$ (i.e. a reduction of $82 \%$ ). Configuration IV produced the minimum tracer gas concentration decay rate. It took approximately 69 minutes for the tracer gas to decay to the background concentration. When both doors and windows were 
closed, the infiltration and exfiltration airflow was through the unintended gaps, such as, gaps between floor and door, roof and wall, etc.

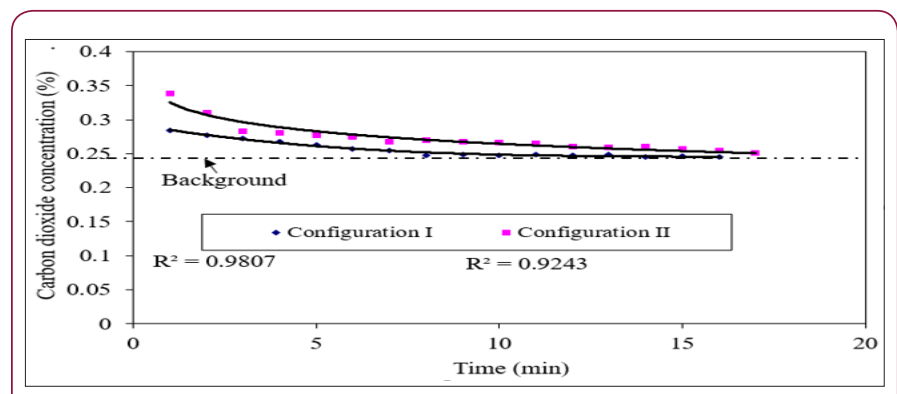

Figure 3: Tracer gas concentration decay for configuration I and II.

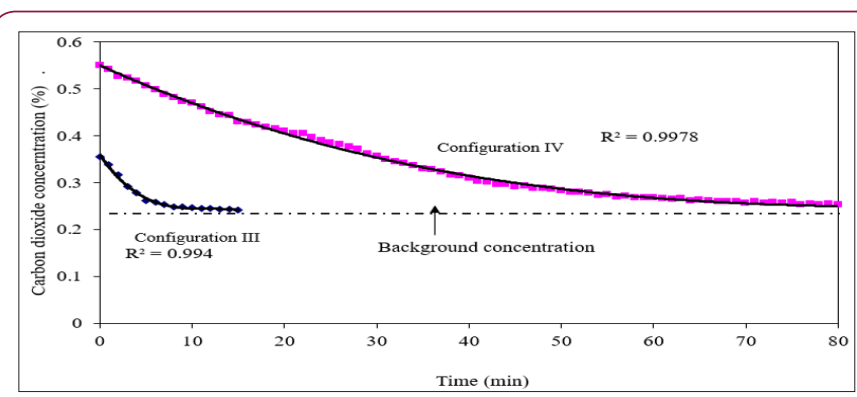

Figure 4: Tracer gas concentration decay for configuration III and IV.

With reference to Figures $3 \& 4$ and taking a reference initial tracer gas concentration of $0.28 \%$ the time taken for the tracer gas concentration to decay to the background concentration varied depending on the type of the ventilation components in use. Table 2 summarizes the time taken for the carbon dioxide concentration to decay from $0.28 \%$ to the background concentration. From Table 2 windows have a higher ventilation effect (shorter decay time) than doors. However, this depends on the wind speed and direction and the orientation of the ventilation component with respect to the wind direction. Somerset East experience $W\left(60^{\circ} \pm 15^{\circ}\right) \mathrm{N}$ prevailing winds, and when windows are open, and doors closed, the west side windows capture the prevailing winds which then escape through the east and south windows, and to a lesser extent through the north side windows. This gives an effective controllable air inflow and outflow by adjusting the opening area of windows.

Table 2: Decay periods for different ventilation components status.

\begin{tabular}{|c|c|}
\hline Ventilation components state & Decay period (minutes) \\
\hline All doors and windows open & 14 \\
\hline $\begin{array}{c}\text { All doors closed and windows } \\
\text { open }\end{array}$ & 17 \\
\hline $\begin{array}{c}\text { All windows closed, and doors } \\
\text { open }\end{array}$ & 18 \\
\hline All windows and doors closed & 69 \\
\hline
\end{tabular}

In the case where windows are closed and doors open, the west side door captures the prevailing winds. Since the prevailing winds are not purely westerly, components of the inflow air currents also penetrate through the north side door. These currents are then opposed by the inflow air current through the west side door which will try to escape though the north side door as it is the only designed escape path under this configuration. This results in reduced concentration decay time, implying a reduced air exchange rate as compared to when windows are open, and doors closed. From Table 2 windows have a higher ventilation effect (shorter decay time) than doors. Somerset East experience west-north-west prevailing winds, and when windows are open, and doors closed, the west side windows capture the prevailing winds which then escape through the east and south windows, and to a lesser extent through the north side windows. This gives an effective controllable air inflow and outflow by adjusting the opening area of windows.

In the case whereby windows are closed, and doors open, west side door capture the prevailing winds. Since the prevailing winds are not purely westerly, components of the inflow air currents also penetrate through the north side door, and these are then opposed by the inflow air current through the west side door which will try to escape though the north side door as it is the only designed escape path under this configuration. This results in reduced concentration decay time, implying a reduced air exchange rate as compared to when windows are open, and doors closed.

\section{Air Quality}

Several decays periods can be observed from Figures 3 \& 4 . For each period, the initial and final times were determined and a normalized concentration, $\mathrm{Cn}$, was calculated for each measurement time:

$$
C_{n}=\frac{C(t)-C(0)}{C(0)-C_{0}}
$$

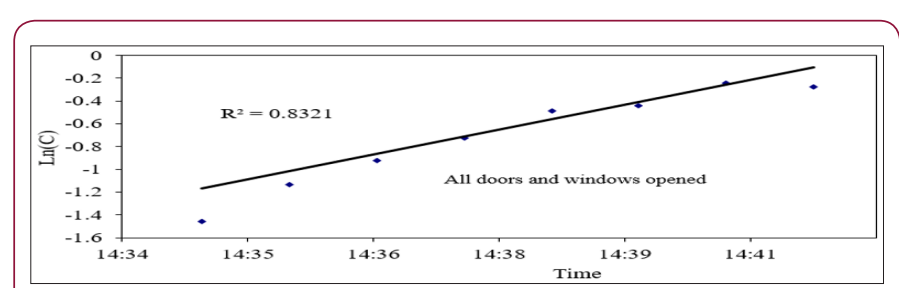

Figure 5: Logarithmic graph of concentration: All doors and windows closed.

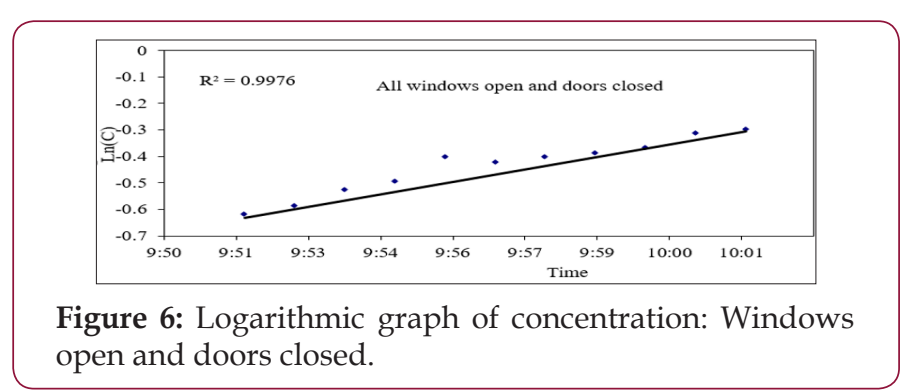

where $\mathrm{C}(0)$ is the initial concentration at the beginning of the decay period. A base outdoor concentration was determined from the minimum values at the end of long decay periods and it was seen to be about $0.234 \%$. This outdoor concentration was first deducted from the carbon dioxide concentration to get the increase resulting from the instant of injection. (Figures 5-8) show the graphs of $\mathrm{Ln}(\mathrm{Cn})$ versus time for different ventilation 
component configurations. The air change rate, which is the slope of the line that represents $\mathrm{Ln}(\mathrm{Cn})$ versus time was calculated for each graph. Table 3 shows the specific airflow rates for different ventilation component configurations. In this table, the confidence intervals were calculated from the dispersion of the concentration measurements around the regression line, using $0.1 \%$ probability $(99.9 \%$ confidence). When all the designed ventilation components were closed the least air exchange rate of (0.29 0.03) h-1 was observed as compared to other ventilation component configurations. The equivalent outdoor airflow rates for each ventilation component configurations were calculated by multiplying the air exchange rate by the house volume. The house has a volume of $34.56 \mathrm{~m} 3$ and an envelope area of $61.1 \mathrm{~m}^{2}$. If the flows are due to the envelope leakage the specific leakage rate was obtained by dividing the flow rate by the envelope area and results are summarized in Table 3.

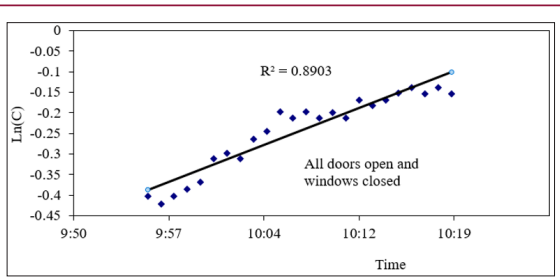

Figure 7: Logarithmic graph of concentration: Doors open and windows closed.

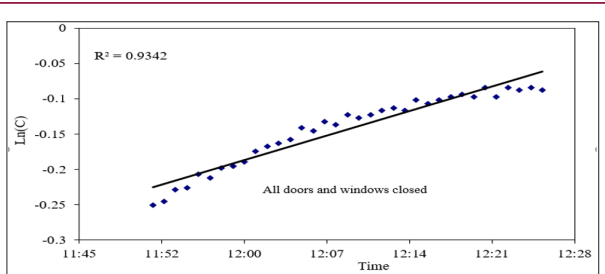

Figure 8: Logarithmic graph of concentration: All doors and windows closed.

Table 3: Specific airflow rates calculated from the various $\mathrm{CO}_{2}$ concentration decays.

\begin{tabular}{|c|c|c|c|c|}
\hline & $\begin{array}{c}\text { Ventilation } \\
\text { component status }\end{array}$ & $\begin{array}{c}\text { Specific air } \\
\text { exchange } \\
\text { rate }\left(h^{-1}\right)\end{array}$ & $\begin{array}{c}\text { Equivalent } \\
\text { outdoor air } \\
\text { flow rate } \\
\left(\mathrm{m}^{3} / \mathrm{h}\right)\end{array}$ & $\begin{array}{l}\text { Specific } \\
\text { leakage } \\
\text { rate } \\
\left(\mathrm{m}^{3} / \mathbf{h} \cdot \mathbf{m}^{2}\right)\end{array}$ \\
\hline A & $\begin{array}{c}\text { Doors and windows } \\
\text { open }\end{array}$ & $9.58 \pm 0.04$ & $\begin{array}{c}331.08 \pm \\
1.38\end{array}$ & 5.42 \\
\hline B & $\begin{array}{l}\text { Doors closed and } \\
\text { windows open }\end{array}$ & $1.74 \pm 0.02$ & $60.13 \pm 0.69$ & 0.98 \\
\hline $\mathrm{C}$ & $\begin{array}{l}\text { Doors open, and } \\
\text { windows closed }\end{array}$ & $0.84 \pm 0.04$ & $29.03 \pm 1.38$ & 0.48 \\
\hline D & $\begin{array}{c}\text { Doors and windows } \\
\text { closed }\end{array}$ & $0.29 \pm 0.03$ & $10.02 \pm 1.04$ & 0.16 \\
\hline
\end{tabular}

The ventilation rate determines the indoor environment, as the incoming air carries with it thermal energy. If the outdoor temperature is higher than the indoor, and as the outdoor air flows indoors, the tendency is to raise the indoor temperature. The rate of ventilation heat flow is approximated by equation: $Q_{v}=1200 \dot{V} \Delta T$. Taking the mean indoor-outdoor temperature difference $\Delta T$ to be $7^{\circ} \mathrm{C}$ and the ventilation rates from Table 3 , the ventilation heat flow rates were calculated. Table 4 shows the summary of results for the rate of ventilation heat flows for different ventilation component configurations. Depending on the indoor and outdoor temperature difference, configuration A (from Table 4) which has the highest rate of ventilation heat flow, can result in excess heat gains or loses. However, adjusting the effective open areas of the ventilation components can regulate the heat gain/loss, thus keeping the indoor environment within the comfort levels. It must be noted that the rate of ventilation heat flow for configuration D is through the unintended ventilation path ways, i.e. through gaps between doors and floors, etc, since all designed ventilation components were closed.

Table 4: Ventilation heat flow rate for different ventilation components configuration.

\begin{tabular}{|c|c|c|}
\multicolumn{4}{|c}{} & $\begin{array}{c}\text { Ventilation component } \\
\text { configuration }\end{array}$ & $\begin{array}{c}\text { Rate of ventilation heat } \\
\text { flow (J/s) }\end{array}$ \\
\hline A & Doors and windows open & 772 \\
\hline B & Doors closed and windows open & 140 \\
\hline C & Doors open, and windows closed & 68 \\
\hline D & Doors and windows closed & 24 \\
\hline
\end{tabular}

Figure 9 shows the moving average of the tracer gas concentration, while Figure 10 shows the variation of wind speed and carbon dioxide concentration. It is worth to mention that on the day of taking measurement it was drizzling with a mean indoor and outdoor temperature difference of about $7^{\circ} \mathrm{C}$. The mean wind speed was about $0.6 \mathrm{~m} / \mathrm{s}$ and blowing from $\mathrm{W} 60^{\circ} \mathrm{N}$. The drizzling forced occupants to get indoor early. From Figure 10 before 5:30 PM the carbon dioxide concentration was almost constant and slightly greater than the background concentration by about $0.009 \%$. At 5:30 PM the concentration abruptly increased to $0.245 \%$ and remained constant for about $1 \mathrm{~h} 30$ minutes. It can be observed that as from 5:45 PM the carbon dioxide concentration abruptly increased to $0.248 \%$ and then levels out but some fluctuations. This sharp increase might have been attributed to the closing of the remaining open windows and probably with all the occupants getting indoors resulting in more carbon dioxide production. It was also the time when the occupants started to prepare for supper, resulting higher production of carbon dioxide. The fluctuations might be due to frequent opening and closing of doors. Two major drops in carbon dioxide concentration can be noticed, one occurring as from 9:50 PM to 10:30 PM and the other from 01:50 AM to 4:15 AM.

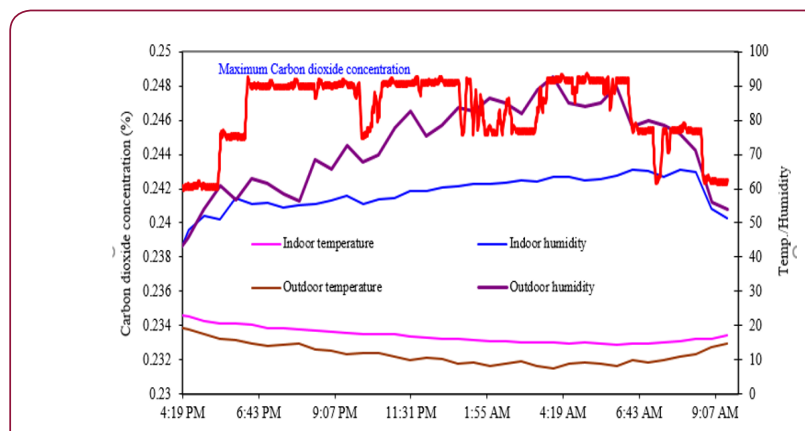

Figure 9: Indoor air quality. 


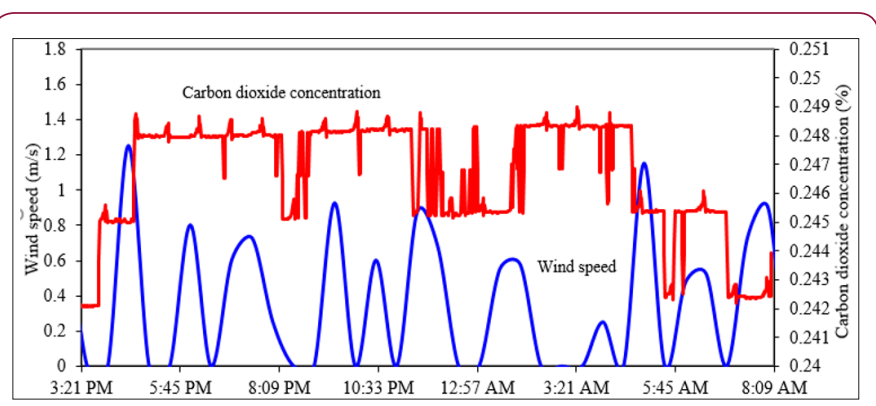

Figure 10: Wind speed and carbon dioxide concentration.

A prolonged opening of some doors might have caused the drop-in carbon dioxide concentration. It is also worth to note that the toilet is outdoor and that that windows were never opened throughout the night. On the day of taking measurements two of the occupants were smokers and were not allowed to smoke indoor. So, the need to smoke resulted in the opening and closing of doors and resulting in the fluctuations in carbon dioxide concentration. The ventilation rate depends on the wind speed and direction, and the fluctuations in wind speed and directions results in the smaller fluctuation amplitudes in carbon dioxide concentration. From Figure 10 it can be noted that the two drops in carbon dioxide correspond to a sudden drop in wind speed. At 6:00 AM the school child started preparing to go to school and the opening of doors result in the drop in the carbon dioxide concentration. The occupants are of old age they wake up late at around 8:00 AM and this is noticed in the sudden drop in the carbon dioxide concentration when they open most of the ventilation components. According to the South African Indoor Air Quality Code, the indoor carbon dioxide concentration should be less than $0.500 \%$. With reference to Figure 9 the indoor carbon dioxide concentration never exceeded the maximum limit of $0.500 \%$. This implies the passive solar house has a well-ventilated design, which does not require any mechanical device for ventilation to maintain the air quality within the recommended range. Using equation 1, i.e. $Q_{e}=\frac{n S}{C_{i}-C_{0}}$, and taking S $=20 \mathrm{l} / \mathrm{h}, C_{i}=0.248,=0.234$ and $\mathrm{n}=5$ (number of occupants) the equivalent outdoor airflow rate per person was found to be $7.142 \mathrm{~m}^{3} /$ (h. person).

\section{Conclusion}

Through proper house design, considering the orientation of the house in relationship to the daily and seasonal sun's path, and considering the direction of the prevailing winds, the indoor environment can be maintained within the thermal comfort zone. Through the correct operation of the designed ventilation components (that is, windows and doors) natural ventilation can be effective in maintain the recommended indoor air quality. Natural ventilation varies greatly on a daily and seasonal basis, as well as local factors including wind speed and temperature, which also influence the frequency of windows opening. The ventilation rate was found to depend on the ventilation component in use, windows were found to have a higher ventilation effect than doors. Correct opening and closing of windows can regulate the air infiltration thus controlling the indoor air quality. An equivalent outdoor per person was found to be $7.142 \mathrm{~m}^{3} /$ (h.person).

The carbon dioxide concentration measured over night when most of the ventilation components were closed and all occupants were indoor never exceeded the recommended limit of $0.500 \%$, but only attained a maximum of $0.248 \%$. The house has therefore a good indoor air quality. By opening curtains during daytime artificial daylighting can be avoided, thus reducing electrical lighting energy consumption. Due to the ever increase in price of energy there is need to apply ventilation strategies to maximize building performance, air quality, and energy efficiency. Buildings must be airtight to reduce uncontrollable air leakages. Correct differential pressure and rate of airflow result in a thermally comfortable indoor environment.

\section{References}

1. Klunne WE (2003) Energy efficient housing to benefit South African households. Boiling point 48.

2. Basset M, Gibson F (1999) Indicators of ventilation effectiveness in twelve New Zealand schools. Proceedings of indoor air p. 99.

3. Elisabeth G, Gratia S, Andre De Herde (2003) Design of low energy office buildings. Energy and buildings 35(5): 473-491.

4. Erwewty Howes R, Fainberg A (1991) The Energy Sourcebook: A guide to Technology, Resources and Policy, American Institute of Physics.

5. Myers E George (2004) Effect of ventilation rate and board loading on formaldehyde concentration: a critical review of literature. Forest products Journal 34(10).

6. Roulet (1991) Simple and cheap air change rate measurement using $\mathrm{CO}_{2}$ Concentration decays. Air infiltration and ventilation centre Technical Note: 34 .

7. Smith PN (1988) Determination of ventilation rates in occupied buildings from metabolic $\mathrm{CO}_{2}$ concentrations and productions rates. Building \& Environment 23(2): 95-102.

8. Penman (1982) Experimental determination of airflow in a naturally ventilated room using metabolic $\mathrm{CO}_{2}$. Building and Environment 17(4): 253-256.

9. Agrement South Africa (2002) Assessment criteria: Building and walling systems: Acoustics performance of buildings. 


\section{ISSN: 2574-1241}

DOI: $10.26717 / B J S T R .2018 .08 .001610$

Golden Makaka. Biomed J Sci \& Tech Res

(c) This work is licensed under Creative

Submission Link: https://biomedres.us/submit-manuscript.php

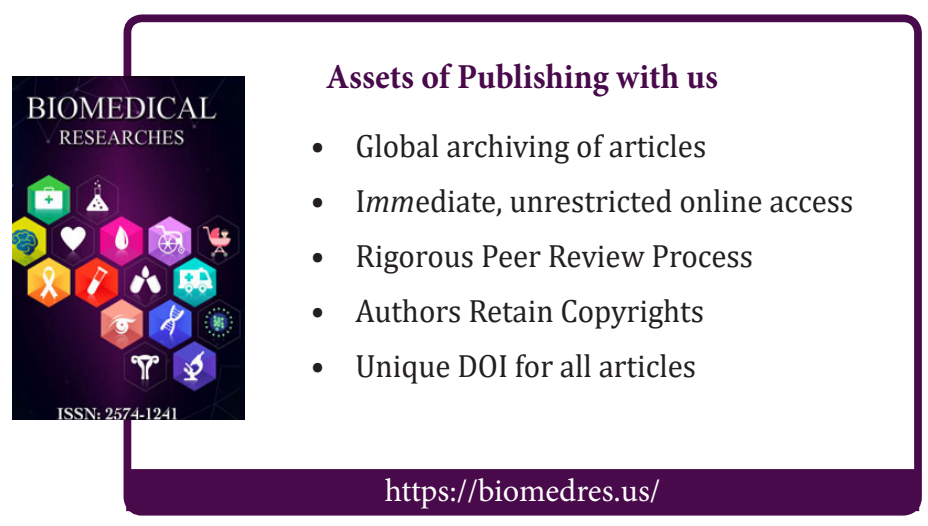

